УДК 338.43. 02 (510) (043.3)

ББК 65.9(4/8)

НОВОЕ НАПРАВЛЕНИЕ СОЦИАЛЬНОГО И ЭКОНОМИЧЕСКОГО РАЗВИТИЯ АГРАРНОЙ ОТРАСЛИ КИТАЯ

с. с. ПОЛОНИК

econauka@,bsu.by

доктор экономических наук, профессор, заместитель декана по научной работе

экономического факультета

Белорусский государственный университет

Минск, Республика Беларусь

М. А. СМОЛЯРОВА

marynasmoliarova@mail.ru

кандидат экономических наук, доцент кафедры аналитической экономики

и эконометрики экономического факультета

Белорусский государственный университет

Минск, Республика Беларусь

В статье разработаны организационно-экономический механизм реформирования сельского хозяйства Китая; модель зависимости между уровнем кооперации в сельском хозяйстве Китая и ростом благосостояния населения. Определена роль поселкововолостных предприятий в успешности реформирования сельского хозяйства Китая.

Ключевые слова: сельское хозяйство, реформы, продовольственная безопасность, организационно-экономический механизм, поселково-волостные предприятия, сельскохозяйственная продукция.

\title{
NEW DIRECTION OF SOCIAL AND ECONOMIC DEVELOPMENT OF THE AGRICULTURAL SECTOR OF CHINA
}

\section{S. S. POLONIK}

Doctor in Economics, Professor, Deputy dean for science

of the faculty of Economics

Belarusian State University

Minsk, Republic of Belarus

M. A. SMOLYAROVA

$\mathrm{PhD}$ in Economics, Associate Professor of Chair of analytical economics

and econometrics of the faculty of Economics

Belarusian State University

Minsk, Republic of Belarus

The article describes the organizational and economic mechanism of reforming of China's agriculture; the model of the relationship between the level of cooperation in agriculture in China and the growth of the well-being of the population. The role of village-township enterprises in the success of reforming China's agriculture has been determined.

Key words: agriculture, reforms, food security, the organizational and economic mechanism, village-township enterprises, agricultural products. 


\section{ВВЕДЕНИЕ}

Сельское хозяйство Китая является главной отраслью народного хозяйства, обеспечивающей продовольственную безопасность страны. Поэтому реформирование сельского хозяйства в Китае осуществляется последовательно и качественно с трансформацией форм собственности и способов применения организационно-правовых и экономических методов и инструментов управления хозяйственной деятельности, направленное на повышение эффективности взаимодействия хозяйствующих субъектов между собой и с государственными органами.

\section{РЕЗУЛЬТАТЫ И ИХ ОБСУЖДЕНИЕ}

Для разработки методологии и координации реформ создан Государственный комитет по развитию и реформе (см. таблицу 1).

Таблица 1 - Составные элементы организационно-экономического механизма управления реформой в КНР

\begin{tabular}{|l|l|}
\hline Макроуровень & $\begin{array}{l}\text { Планирование реформы (Центральный Комитет Коммунистической партии } \\
\text { Киратегическое управление (Центральный Комитет Коммунистической } \\
\text { партии Китая (ЦК КПК), Государственный комитет по развитию и реформе). } \\
\text { Нормативно-правовое обеспечение }\end{array}$ \\
\hline Мезоуровень & $\begin{array}{l}\text { Ценообразование на продукцию (двухколейная система). } \\
\text { Налогообложение и страхование. } \\
\text { Кредитование }\end{array}$ \\
\hline Микроуровень & Организация самоуправления и кооперации \\
\hline
\end{tabular}

Источник: составлено автором

На макроэкономическом уровне планирование (пятилетние планы) организуется Центральным комитетом компартии Китая. Весь процесс от составления предварительного проекта до принятия плана занимает примерно один год. В создании документа участвуют 5-6 тысяч человек.

На мезо- и микроуровнях - ключевые звенья «китайской модели реформирования»: семейный подряд, двухколейная система и самоуправление.

На микроуровне: управление организацией и формированием механизмами самоуправления и кооперации поселково-волостных предприятий и личных хозяйств.

Успешность реформы зависит от правильного определения движущих сил реформирования и создания благоприятных условий (деловой среды и стимулов) для реализации устремлений государства и хозяйствующих субъектов. Наиболее полно этот подход был воплощен в успешном реформировании сельского хозяйства, которое определено как «реформенный дивиденд» Китая (см. рисунок 1). 


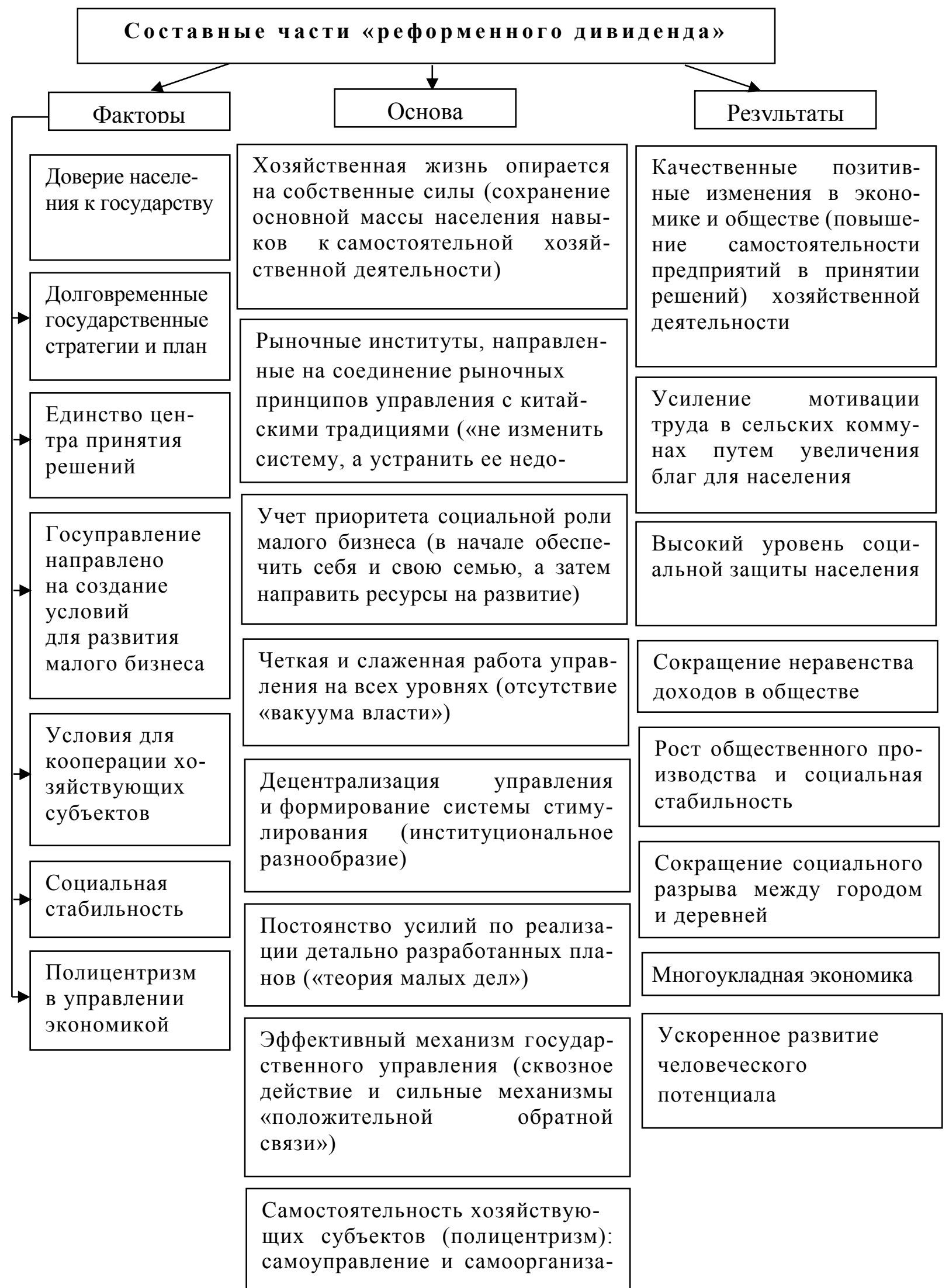

Рисунок 1 - Факторы, основа и результаты «реформенного дивиденда в Китае» Источник: составлено автором 
Формирование государственного управления реформой сельского хозяйства в Китае осуществляется с целью формирования долгосрочного и эффективного механизма по обеспечению продовольственной безопасности и производства сырья для смежных отраслей экономики, а также создания дополнительных рабочих мест в сельской местности и городах. Результаты реформы сельского хозяйства Китая выражаются в росте производства сельхозпродукции: зерновые в 2014 г. - 607,03 млн т (в 2000 г. 462,18 млн т; в 1980 г. - 320,56 млн т); мясо в 2014 г. - 87,07 млн т (в 2000 г. 60,14 млн т; в 1980 г. - 12,05 млн т); овощи в 2014 г. - 760,05 млн т (в 2000 г. 459,77 млн т); фрукты в 2014 г. - 261,42 млн т (в 2000 г. - 62,25 млн т); аквакультуры в 2014 г. - 64,62 млн т (в 2000 г. - 37,06 млн т; в 1980 г. - 4,50 млн т). В 2014 г. отраслевая структура сельского хозяйства Китая имела земледельческую направленность, в которой $54 \%$ занимает растениеводство, 28 \% - животноводство. Основные показатели сельского хозяйства Китая, достигнутые в ходе реформ, приведены в таблице 2.

Таблица 2 - Основные показатели сельского хозяйства в Китае

\begin{tabular}{|l|c|c|}
\hline \multicolumn{1}{|c|}{ Показатели } & 1980 г. & 2014 г. \\
\hline \multicolumn{1}{|c|}{ Показатели сельского хозяйства } \\
\hline Сельское хозяйство в ВВП (млрд USD) & $\begin{array}{c}91,23(29,87 \% \\
\text { от общего) }\end{array}$ & $\begin{array}{c}950,03(9,16 \% \\
\text { от общего }\end{array}$ \\
\hline Сельское население (млн чел.) & $\begin{array}{c}795,65(80,61 \% \\
\text { от общего) }\end{array}$ & $\begin{array}{c}618,66(45,23 \% \\
\text { от общего) }\end{array}$ \\
\hline Число занятых в сельском хозяйстве (млн чел.) & $\begin{array}{c}291,22(68,75 \% \\
\text { от общего) }\end{array}$ & $\begin{array}{c}227,90(29,50 \% \\
\text { от общего) }\end{array}$ \\
\hline Количество волостей и поселков (ед.) & 54183,00 & 33162,00 \\
\hline Количество поселково-волостных предприятий (млн ед.) & - & 31,11 \\
\hline Количество комитетов сельских жителей (тыс. ед.) & 709,82 & 588,41 \\
\hline Количество семей в селах (млн дворов) & 176,73 & 268,02 \\
\hline \multicolumn{2}{|c|}{ Макросоциальные показатели } \\
\hline Общая численность населения (млн чел.) & 987,05 & 1367,82 \\
\hline Среднедушевой доход городских жителей (USD) & 320,54 & 4697,72 \\
\hline Среднедушевой чистый доход сельских жителей (USD) & 128,39 & 1708,31 \\
\hline Коэффициент Энгеля семьи городских жителей (\%) & 56,90 & 35,00 \\
\hline Коэффициент Энгеля семьи сельских жителей (\%) & 61,80 & 37,70 \\
\hline $\begin{array}{l}\text { Среднедушевая жилая площадь сельского населения } \\
\text { (чел./м²) }\end{array}$ & 9,40 & 37,10 \\
\hline
\end{tabular}

Источник: составлено автором на основании данных Статистического управления КНР.

Основными элементами стратегии рыночных реформ сельского хозяйства в Китае являются семейный хозяйственный подряд как новая организационная форма экономической деятельности в сельском хозяйстве; «двухколейная система» обращения сельхозпродукции; поселково-волостные предприятия; самоуправление на местном уровне; система кредитования сельскохозяйственных производств и отделение землевладения от землепользования (традиционно пахотная земля является государственной, семья получила право на ее аренду).

Государственное управление реформой сельского хозяйства в Китае выразилось в том, что: сельскохозяйственные предприятия семейного типа стали базой двухъярусной системы, совмещающей индивидуальное и коллективное хозяйствование; были созданы условия для реализации инициативы крестьян и увеличения производства путем разрешения аренды земли; были установлены гарантированные цены на продукцию; было разрешено осуществление других видов экономической деятельности, на базе которых создавались поселково-волостные предприятия. 
Опыт китайских реформ доказал, что для сельских жителей одной реформы сельского хозяйства недостаточно. Требуется всестороннее экономическое реформирование поддерживающих и обслуживающих сельское хозяйство производств, что требует соответствующей технологии управления реформой. В результате: на первом этапе осуществления реформ сельского хозяйства преобразовывались структуры экономики и проводились агротехнические изменения; на втором этапе решилась проблема «питания и тепла»; на третьем этапе сформировались новые направления и отрасли в аграрной экономике, промышленности, строительстве, сфере услуг и торговле.

Ключевым звеном «китайской модели управления реформой сельского хозяйства» является организация «двухколейной системы» обращения продукции, которая явилась формой сосуществования «плана» и «рынка», суть которой состояла в задействовании в аграрной экономике двух структур обращения сельхозпродукции (см. рисунок 2).

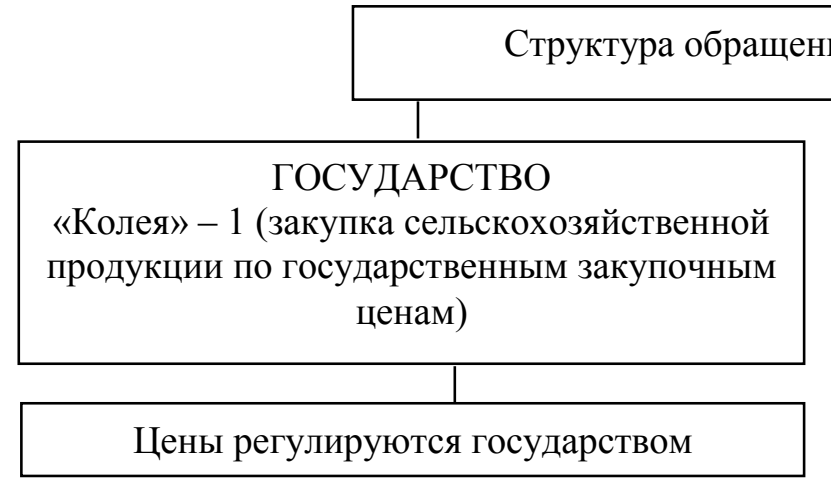

Задача

Обеспечить потребности государства в необходимом объёме продовольствия

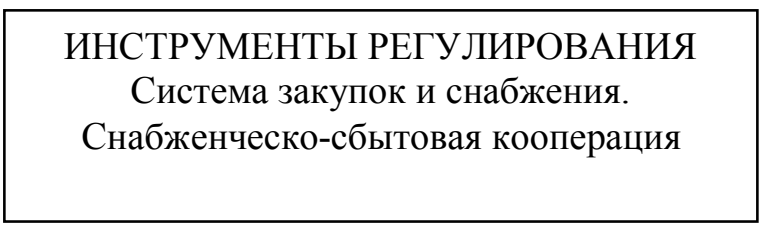

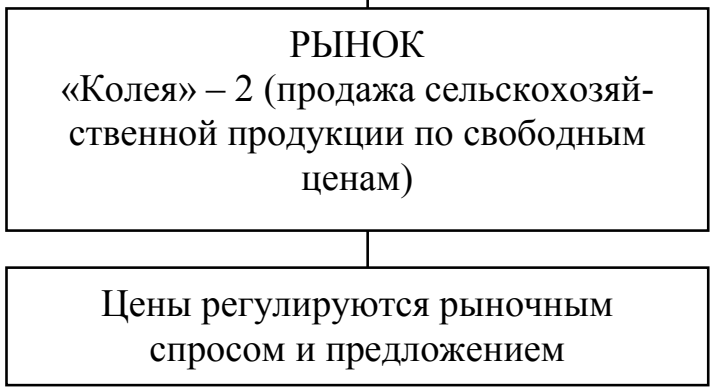

Задача

Обеспечить потребности государства в необходимом объёме продовольствия

ИНСТРУМЕНТЫ РЕГУЛИРОВАНИЯ

Система закупок и снабжения.

Снабженческо-сбытовая кооперация

Рисунок 2 - Сущность двухколейной системы управления производством и обращением сельхозпродукции

Источник: составлено автором

Структура обращения основных видов сельскохозяйственной продукции была разделена на две «колеи» (потоки), которые обслуживались разными механизмами цен (государственным регулированием и соответствием рыночного спроса и предложения), что повлекло постепенное продвижение к рынку и стабильное развитие экономики.

Необходимость создания двухколейной системы была обусловлена тем, что без государственного регулирования и плана нельзя было обеспечить использование рыночного механизма в нужном направлении, преодолеть негативные стороны, характерные для рынка (стихийность, коррупцию, чрезмерные колебания цен, определенную хаотичность, спекуляции, злоупотребление служебным положением и пр.).

Двухколейная система была полностью отменена в 2001 г. после того, как в сельском хозяйстве были сформированы «новый экономический слой» на базе поселково- 
волостных предприятий и новые организационно-правовые условия для их кооперации и самоорганизации в соответствии с рыночными условиями современного сельскохозяйственного производства.

Главным итогом реформы сельского хозяйства Китая явилось формирование в сельской местности «нового экономического пространства» семейных хозяйств и поселково-волостных предприятий, осуществляющих кооперацию на принципах взаимовыгодности и взаимодополнения, обеспечивающих устойчивое развитие сельских территорий при поддержке местного самоуправления. Следствием китайской модели управления реформой сельского хозяйства явился постоянный рост сельхозпроизводства при последовательном снижении уровня государственной поддержки сельского хозяйства. За период с 1995 г. по 2014 г. валовой объем сельхозпродукции увеличился в 6,83 раз (с 243,57 млрд USD до 1664,16 млрд USD), объем сельхозпродукции на душу населения - в 6,05 раз (с 201,10 USD до 1216,65 USD), выработка на одного занятого в сельском хозяйстве - в 10,65 раз (с 685,54 USD в 1995 г. до 7302,15 USD).

Комплексные реформы на всех уровнях (макро, мезо и микро) требуют подготовки взаимоувязанных мероприятий и процедур, интегрированной системы управления и подхода, предусматривающего применение различных инструментов управления реформой, так как их отсутствие является фактором риска при реализации реформ. Проведенное обобщение опыта реформ сельского хозяйства в Китае показывает, что главным в успехе реформ явилось создание государством условий для реализации стремления крестьян повысить уровень своего благосостояния. Это выразилось в соединении рыночных принципов управления с китайскими традициями, в развитии самоуправления и самоорганизации, что в совокупности позволило повысить производительность труда и сократить издержки государственного управления отраслью. Как следствие, это привело к сокращению неравенства в доходах и повышению уровня жизни сельского и городского населения, что подтверждается фактическими значениями показателей Джини и Энгеля.

Изменение показателей Джини и Энгеля в зависимости от темпов роста ВВП и количества рабочих мест в экономике определены по временным периодам, соответствующим этапам реформ: 1980-1990 гг.; 1991-2004 гг.; 2005-2013 гг.

1-й период (1980-1990 г2.)

Создание новых рабочих мест (с помощью поселково-волостных предприятий), как и ожидалось, приводит к росту ВВП (высокий коэффициент эластичности между показателями) и незначительному снижению коэффициента Энгеля, т.е. покупательская способность населения возросла. В то же время, рост занятости и выпуска приводят к росту расслоения в обществе - индекс Джини.

2-й период (1991-2004 г2.)

Снижение коэффициента Энгеля сопровождается ростом занятости.

3-й период (2005-2013 г2.)

Снижение степени социальной дифференциации ведет к дальнейшему заметному росту занятости. При этом стремительно рос ВВП (средний темп $+14,9$ \% в год), а коэффициент Энгеля более плавно, но продолжал снижаться $(-0,8$ \% в год).

Исходя из результатов, можно сделать вывод, что в начале экономических реформ происходит расслоение по доходам. Затем быстрый экономический рост и его торможение приводят к выравниванию уровня жизни. При этом начальным механизмом экономического развития служат организационные и технологические инновации (управление реформой), которые повысили эффективность сельского хозяйства и увеличили рынок новых товаров и услуг, востребованных потребителями. Соотношение коэффициентов Эн- 
геля и Джини можно предложить в качестве индикатора социальной стабильности, качественного экономического роста и общего представления об эффективности государственного управления реформой на примере сельского хозяйства Китая.

Пути решения продовольственной безопасности Китая

Задачей правительства КНР на современном этапе является обеспечение населения продуктами питания без ограничения экспорта традиционных видов сельскохозяйственных культур, не прибегая к импорту пищевых продуктов. Для повышения эффективности использования ресурсов, производительности труда и качества сельхозпродуктов необходимо продолжить формирование эффективной системы продовольственной безопасности Китая на принципах интенсивного ведения сельхозпроизводства.

Решение проблемы обеспечения продовольственной безопасности в Китае на сегодняшний день осуществляется путем поддержки и развития крупных сельскохозяйственных организаций и агрохолдингов. Государственная поддержка крупных организаций дает больший эффект по сравнению с поддержкой малых форм хозяйствования. Чтобы повысить эффективность государственных инвестиций в сельское хозяйство нужно укреплять систему социально-экономических связей органов правительства и сельхозпроизводителей, а также выстроить оптимальную инфраструктуру, включая строительство различных объектов водного хозяйства.

Борьба с загрязнением окружающей среды

Борьба с загрязнением окружающей среды в сельской местности является ключевой задачей китайского правительства. В этой связи государственные программы в области охраны окружающей среды в сочетании с новыми экологическими требованиями к технологиям и оборудованию, законодательного регулирования переработки промышленных отходов позволят существенно улучшить экологию Китая. В настоящее время на государственном уровне формируется система экологического контроля, в которой Всекитайское Собрание народных представителей осуществляет правовой надзор, а исполнительные органы власти на всех уровнях ответственны за исполнение экологического законодательства, территориальные ведомства по охране окружающей среды выполняют единый административный контроль, а заинтересованные учреждения ведут просветительскую работу в данной сфере.

Развитие кредитных сельскохозяйственных кооперативов в регионах

На развитие региональных кредитных сельскохозяйственных кооперативов напрямую влияет уровень социально-экономического развития регионов и степень концентрации кооперационных связей между хозяйствующими субъектами. Действующий в настоящее время организационно-экономический механизм функционирования системы кредитных сельскохозяйственных кооперативов в Китае находится на начальном этапе своего развития, которое происходит пока в условиях ограниченного финансирования и несовершенства законодательной базы, отсутствия единых стандартов деятельности и недостаточной оценки значимости органами местной власти данного института для целей развития территорий и реформирования сельского хозяйства.

Ключом к успешному созданию сети этих кооперативов в различных регионах Китая является наличие спроса на финансовые услуги (ресурсы), научно-организационной поддержки, интереса у потенциальных инвесторов к предоставлению финансовых ресурсов, инициативных групп при создании представительства или филиала кредитного сельскохозяйственного кооператива и государственная поддержка.

Внедрение инноваций в сельское хозяйство Китая

Активизация процессов модернизации сельского хозяйства в КНР должна стать следующим этапом развития отрасли. Современные требования к продуктам питания 
и уровню эффективности сельхозпроизводства в мире обусловили необходимость развития инфраструктуры АПК Китая, привлечение высококвалифицированных специалистов в данную сферу, а также внедрение новых инновационных технологий и процессов. Рост потенциала использования улучшения земель и их интенсивного использования, развитие капитального строительства в данной отрасли будут способствовать ускорению производственных процессов.

В развитии управления реформой сельского хозяйства в Китае важно учитывать эволюцию китайской модели государственного регулирования аграрной экономики в части дальнейшей трансформации земельных отношений и управления земельными ресурсами, развития сельского хозяйства с учетом его многофункциональности и мультипликативности влияния на занятость населения и доходы сельскохозпроизводителей. В первую очередь, это решение проблемы трудоизбыточности аграрного производства и конкуренции личных подсобных хозяйств с крупными хозяйствами. Все это требует формулирования новой социальной парадигмы устойчивого развития сельских территорий на основе создания малых инновационных производств и развития сферы услуг с учетом специфики конкретной сельской территории, а также проведения комплексных исследований проблем управления реформой сельского хозяйства.

Эти меры позволят сократить отток рабочей силы из деревни, а также мотивируют дальнейшее формирование среднего класса в сельской местности Китая.

\section{ВЫВОДЫ}

В КНР разработан организационно-экономический механизм реформирования сельского хозяйства на основе исследования практики и обобщения теории «китайской модели реформирования сельского хозяйства» как государственного управления трансформацией, представляющей собой четкое следование порядку этапов «социальная стабильность - развитие - реформа»; в последовательности преобразований; в приспособлении мирового опыта реформ к традициям Китая после соответствующей экспериментальной проверки и обоснования в теории. Подтверждено, что эффект реформирования определяется не только научной новизной подхода к реформе, но и наличием специальных знаний (организационного обеспечения) о порядке и методах осуществления отдельных мероприятий. Организационное и информационно-аналитическое обеспечение реформ должно быть представлено в виде набора методических рекомендаций по разработке и осуществлению мероприятий реформы, соответствующих уровню и специфике реформирования организационно-управленческой структуры.

Модель зависимости между уровнем кооперации в сельском хозяйстве Китая и ростом благосостояния населения путем сопоставления макроэкономических показателей: коэффициентов Джини и Энгеля, позволила определить систему критериев, в результате можно оценить эффективность управления реформой на примере сельского хозяйства Китая, включая установленные корреляционные связи роста числа поселкововолостных предприятий с увеличением выпуска сельхозпродукции и снижением степени социального расслоения в обществе. Основную массу новых рабочих мест создали поселково-волостные предприятия, вследствие чего значения показателей Энгеля для городских и сельских жителей стали сближаться, а темпы роста коэффициента Джини, показывающего степень социального неравенства, стали замедляться.

В сельском хозяйстве Китая в настоящее время ключевая роль принадлежит поселково-волостным предприятиям в успешности реформирования сельского хозяйства Китая. Поселково-волостные предприятия являются микроагентами аграрной эконо- 
мики и инструментами комбинации подходов в использовании институтов реформирования сельского хозяйства. Поселково-волостные предприятия - это «новое экономическое пространство» в аграрной экономике Китая, охватывающего переработку сельскохозяйственной продукции, промышленное производство, транспорт и перевозки, строительство, торговлю, бытовое обслуживание и общественное питание (выпускаемая ими продукция включает сельскохозяйственные машины и оборудование, сельхозпродукты и продукцию подсобных промыслов, предметы быта, продовольственные продукты, изделия легкой промышленности).

В настоящее время ведется работа по совершенствованию управления реформированием сельского хозяйства Китая, в частности, укрепления продовольственной безопасности путем формирования продовольственных балансов с учетом различий регионов и комплексного применения методов внешнего и внутреннего регулирования сельхозпроизводством, повышения уровня экологической безопасности сельхозпроизводства за счет инноваций и внедрения экологических стандартов, а также принятие дополнительных мер по сокращению оттока рабочей силы из деревни путем увеличения затрат на социальное обеспечение, пенсионное содержание и создание системы гарантий поддержки пожилых людей в деревне.

\section{СПИСОК ИСПОЛЬЗОВАННЫХ ИСТОЧНИКОВ}

1. Полоник, С. С. Современная экономика Китая / С. С. Полоник, Ван Чао. Минск: «Право и экономика», 2016. - 169 с.

2. Сюй, Даньтун Управление реформой сельского хозяйства в Китае: технологии, механизмы, результаты / Даньтун Сюй, Б. Н. Паньшин // Экономика и предпринимательство. - 2014. - № 12. - С. 258-263.

3. Жуджунь, Дин Путь к рыночной экономике (китайская модель реформ) / Дин Жуджунь, М. М. Ковалев. - Минск: Издательский центр БГУ, 2005. - 384 с.

\section{REFERENCES}

1. Van Chao Sovremennaja Economica Kitaja / Van Chao, S. S. Polonik. - Minsk: «Pravo i ekonomika». - 2016. - 169 s.

2. Suj, Dan'tun Upravlenije reformoj sel'skogo khozyajstva v Kitaje / Dan'tun Suj, Panshin B.N. // Economika i predprenimatel’stvo. - 2014. - № 12. - S. 258-263.

3. Zhujun, Din Put' k pynochnoj economike (kitajskaja model' reform) / Din Zhujun, M. M. Kovalev. - Minsk: Izdatel'skij tsenter BSU, 2005. - 384 s.

Статья поступила в редакиию 2 апреля 2018 года. 